\title{
Audiencias y caso policial en Argentina. Un análisis en recepción
}

\section{Audiences and police news in Argentina. An analysis at reception}

http://dx.doi.org/10.18566/comunica.n43.a03

Fecha de recepción: 9 de noviembre de 2020

Fecha de aceptación: 13 de noviembre de 2020

\section{Resumen}

El presente trabajo se inscribe en una investigación más amplia que tiene por objetivo, por un lado, analizar las condiciones de producción de los programas de la televisión abierta, con especial atención en los casos policiales, el discurso político y la vida de las celebrities, entre otros de resonancia mediática; por el otro, realizar un estudio en recepción con el propósito de indagar en las percepciones de los televidentes y las televidentes en torno a los programas y el tratamiento sobre casos específicos. Aquí se presenta un análisis en recepción sobre el tratamiento mediático del asesinato de Fernando Pastorizzo, cometido por Nahir Galarza; para ello se hicieron entrevistas y se utilizó una metodología cualitativa. Los resultados obtenidos indican que entre la instancia de producción y recepción hubo concordancia en varios aspectos; entre ellos se evidenció desconocimiento o confusión sobre qué significa la violencia de género.

\section{Abstract}

This work is part of a broader investigation that aims, on the one hand, to analyze the conditions of production of open television programs, with special attention to police cases, political discourse and the lives of celebrities, among others; media resonance; on the other, to carry out a study at reception with the purpose of investigating the perceptions of viewers regarding the programs and the treatment of specific cases. Here we present an analysis at the reception on the media treatment of the murder of Fernando Pastorizzo by Nahir Galarza, for this, interviews were conducted and a qualitative methodology was used. The results obtained indicate that between the instance of production and reception there was agreement in several aspects, among them, there was evidence of ignorance or confusion about what gender violence means. comunicación

número 43

Julio - diciembre

2020 | pp. 32-48

\section{María Paula Gago}

Doctora en Ciencias

Sociales. Investigadora del

Instituto de Investigaciones

Gino Germani de la

Universidad de Buenos

Aires.

maría_paula_gago@

hotmail.com

http: / / orcid.org/0000-00018148-1499.

\section{Yamila Heram}

Doctora en Ciencias Sociales. Investigadora del Instituto de Investigaciones Gino Germani de la Universidad de Buenos Aires.

yaheram@yahoo.com.ar https: / / orcid.org/0000-

0002-9209-4571

Palabras clave Televisión, recepción, audiencias, violencia de género, caso policial.

\section{Keywords}

Television, reception, audiences, gender violence, police news. 


\section{Introducción}

En un contexto de desplazamientos hacia otras formas de consumo y microsegmentación de las ofertas, entendemos que la televisión abierta es el lugar privilegiado de producción de discursos para los grandes públicos, a diferencia de la segmentación de las ofertas de la televisión por cable, la televisión on demand y los servicios de streaming. Los acelerados cambios tecnológicos en las formas de distribución de contenidos audiovisuales digitales inciden en las lógicas de producción, y cada vez más se pone el acento en el uso de los datos de las audiencias y la programación algorítmica para la personalización de consumos; no obstante, la televisión continúa siendo relevante como indicador de la circulación de los contenidos masivos. Considerado entonces desde la lógica de la producción discursiva (tematización, producción de agenda), un producto mediático propone una modelización de identidades sociales; como esas identidades se inscriben en lógicas de ciudadanía por hipótesis hay en ellas el intento por configurar modelos dominantes de los intereses y preocupaciones colectivas.

Es por ello que en este artículo interesa acercarnos a las múltiples y diversas formas en que los televidentes y las televidentes interpretan y perciben dichos contenidos a partir del análisis puntual de un caso de gran resonancia mediática. El objetivo del trabajo es analizar las percepciones de aquellos y aquellas sobre el tratamiento que recibió el asesinato de Fernando Pastorizzo en los programas de la televisión argentina. La joven Nahir Galarza utilizó el arma reglamentaria de su padre policía para disparar contra la víctima. Fue condenada a prisión perpetua en julio de 2018 tras un juicio de gran exposición mediática difundido públicamente como "caso Nahir Galarza". Por el fuerte impacto que generó en la agenda de medios y en la opinión pública, este crimen puede considerarse un caso “conmocionante" (Fernández Pedemonte, 2010).

Este trabajo se sustenta en una investigación mayor, que tiene por objetivo articular en dos dimensiones las problemáticas de la cultura masiva. Por un lado, realizar un análisis de los programas de la televisión abierta del área metropolitana en los que predomina el panelismo (profundizando en los casos policiales, el discurso político y las celebrities). Por el otro, hacer análisis en recepción con el propósito de indagar en las percepciones en torno a los tratamientos sobre casos específicos.

Los resultados obtenidos en un trabajo previo sobre este mismo caso policial, en el que se indagó sobre la instancia de producción en los programas de panelismo (Heram y Gago, 2019), arrojaron los principales hallazgos en torno al tratamiento: escasa diversidad de opiniones, ausencia de perspectiva de género, predominancia de un encuadre que enfatizó el carácter histórico y ejemplar del fallo. 
En continuidad con dicho análisis, este trabajo indaga sobre la instancia recepción. La metodología utilizada se centra en un abordaje cualitativo. Asimismo, se hicieron entrevistas a televidentes de la Ciudad Autónoma de Buenos Aires, de más de 18 años, que asumieron haber seguido el caso y tener un consumo diario de televisión no menor de tres horas, de acuerdo con el promedio de la Encuesta Nacional de Consumos Culturales 2017 (SInCA, 2017).

El artículo está organizado en un primer apartado de antecedentes y marco referencial, seguido por la metodología, para así llegar a los principales resultados y, por último, a las conclusiones.

\section{Marco referencial y antecedentes}

Esta investigación aborda las problemáticas de la cultura masiva a partir de un análisis en recepción de un caso policial. En ese sentido, es relevante realizar algunas consideraciones en torno a estos dos aspectos.

En primer lugar, este trabajo se sustenta en una extensa tradición proveniente de los estudios culturales británicos sobre el análisis en recepción. Por solo nombrar algunas referencias clásicas que han realizado los aportes más valiosos, aparecen Hoggart (1957) y su libro Los usos de la alfabetización, Hall (1979) con "Codificar/decodificar" y Morley (1992) con Televisión, audiencias y estudios culturales. A partir de la segunda generación de los estudios culturales se produce el "giro etnográfico" (Mattelart y Neveu, 2002), que lleva a que las investigaciones se diversifiquen y se desplacen nociones claves como la de clase social (las investigaciones de audiencia de Morley dan cuenta de ello). Sin embargo, los conceptos y abordajes de los estudios culturales nos permiten reflexionar en el cruce y relación entre la televisión y la recepción, entendiéndolo como una articulación compleja que se enmarca en contextos y tradiciones más amplias.

En la región, el interés por la recepción se remonta periféricamente a los inicios del campo comunicacional en 1970. Verón (1995) menciona en una entrevista que "la recepción no se estudiaba porque costaba caro (...) la cuestión del trabajo de campo siempre me había parecido esencial" (1995, p. 17). Uno de los primeros trabajos lo situamos en Chile, "La televisión y los sectores populares" (Mattelart y Piccini, 1974). En la década de 1980, a partir de uno de los libros faro del campo comunicacional latinoamericano (De los medios a las mediaciones, 1987, de Martín Barbero), comienza a desplazarse la preocupación hacia la recepción, y ya en 1990 el consumo y la recepción se convirtieron en una de las preocupaciones dominantes del campo (García Canclini, 1995; Landi et al., 1990; Terrero, 1997; Mata, 1997; Grimson y Varela, 1999, entre otros). 
En la actualidad existe un amplio abanico de trabajos que se ocupan de reflexionar sobre los conceptos y definiciones (Jacks, 2011; Saintout y Ferrante, 2006; Grillo et al., 2016, entre otros). Diversos autores plantean la polisemia de sentido en torno al consumo y recepción, lo que acarrea que en muchas ocasiones sean usados indistintamente (Jacks, 2011; Grillo et al., 2016). Es interesante la propuesta de Checa Montúfar (2011), quien reflexiona sobre lo "insuficiente" del término recepción y se pregunta si no se debería pensar en términos de consumo.

En este sentido, es importante señalar que si bien pertenecen a un mismo campo semántico, existen matices entre consumo, recepción, apropiación y uso. El trabajo de Grillo et al. (2016) resulta interesante para comprender el consumo, la recepción y la apropiación como momentos de un mismo proceso que los van incluyendo. Sin desconocer las tensiones entre los conceptos, para el presente proyecto nos centramos en la recepción entendiéndola así:

Una actividad que supone, en primer lugar, la comprensión del código lingüístico, pero también la interpretación como acceso al sentido de la pieza (...) la interpretación no es individual, retoma matrices de la cultura, de los grupos sociales de pertenencia y de los marcos experienciales en los que los receptores están inmersos (Grillo et al., 2016, p. 46).

También cabe aclarar que si bien pertenecen a un mismo campo semántico, se producen distinciones conceptuales entre público y audiencia (McQuail, 1999); Garay Cruz, 2006; Focás, 2017, entre otros): el público es entendido como una dimensión mayor que la audiencia, una que la constituye, no así a la inversa: "Los públicos se forman en función de intereses comunes, son audiencias más estables a través del tiempo y suelen responder de manera más activa a lo que les suministra el medio de comunicación elegido" (Garay Cruz, 2006, p. 7). Por ello, en este trabajo utilizamos la noción de audiencia por ser el conjunto de destinatarios/as a los que se dirigen los mensajes de un medio de comunicación.

Por último, cabe mencionar que en Argentina, en los últimos años, se ha producido una serie de trabajos sobre el análisis empírico en torno al consumo o recepción que han ampliado los antecedentes con respecto a la temática haciendo foco en diferentes aspectos: inseguridad, niñez, medios comunitarios, programas de entretenimiento, género y sexualidades, entre otros (Calzado et al., 2020; Becerra et al., 2020; Wortman, 2015; Moguillansky y Papalini, 2017; Focás, 2017; Moguillansky y Aliano, 2017; Heram, 2018; Duek, 2014; Segura et al., 2018; Justo von Luzer et al., 2018; Boito, et al., 2017, entre otros). 
Por otra parte, se tomó un caso de la agenda policial por varios motivos. En primer lugar, el relato policial ocupó un lugar central en los orígenes del proceso de configuración de la prensa moderna, con la finalidad no solo de ganar lectores a partir de la publicación de notas "escabrosas", sino también de dar cuenta de las nuevas condiciones de vida en ciudades que crecían aceleradamente sin inversión en servicios públicos. Así que la noticia policial, en su primera etapa moderna, tuvo una intencionalidad política, aún vigente, ya sea para denunciar la incapacidad de los gobiernos de resolver el delito o para argumentar la instauración de políticas conservadoras, duras y excluyentes (Martini y Pereyra, 2009).

Por otro lado, se retoma la noción de delito como instrumento crítico ideal (Ludmer, 1999). Esto es, como una frontera móvil y cambiante que no solo sirve para separar la cultura de la no cultura, sino que también articula diferentes zonas como el Estado, la política, los sujetos, la literatura. Desde este punto de vista, se define a la noticia policial como un espacio desde el que se demanda control social (Garland, 2005) y que a la vez cumple con una función pedagógica al delimitar qué es lo correcto, qué no lo es y de qué manera la ciudadanía debe "defenderse" de los peligros que acechan la vida urbana. En este sentido, las series informativas que instalan determinadas modalidades delictivas habilitan modos de reclamos de la prensa para pedir castigos ejemplares o para modificar o sancionar leyes.

Por eso, se resalta la importancia de estudiar este tipo de noticia, que, más allá de su aspecto "morboso", es un relato político y pedagógico (Saítta, 2013), que delimita lo permitido y lo prohibido y demanda control social (Garland, 2005).

\section{Metodología}

Para esta investigación, la técnica metodológica es la entrevista, por cuanto "es una estrategia para hacer que la gente hable sobre lo que sabe, piensa y cree" (Guber, 2011, p. 69). Este trabajo es el fruto de un primer estudio exploratorio y la muestra resulta significativa del universo que se propuso indagar; la selección de los individuos está en relación con el objetivo de la investigación, en el sentido de lo que menciona Flick (2004) sobre la determinación a priori de la estructura de la muestra.

Nos interesó acercarnos a los televidentes y las televidentes mayores de 18 años, de diferentes edades e identidad de género, que asumieron haber seguido el caso y que tuvieron un consumo diario de televisión de tres horas, de acuerdo con el promedio de la Encuesta Nacional de Consumos Culturales 2017 (SInCA, 2017). En cuanto a la cantidad de entrevistas, siguiendo a Glaser 
y Strauss (1967), se tuvo en cuenta el principio o categoría de saturación, por el cual fueron seleccionadas 14 de ellas. Esta investigación es de corte cualitativo y no tiene pretensiones de exhaustividad (Denzin y Lincoln, 2012).

La muestra de los/as entrevistados/as es de carácter casual o incidental; para evitar la sobrerrepresentación de personas vinculadas con las ciencias sociales se utilizaron estrategias que ayudaron a construir un grupo lo más heterogéneo posible. La convocatoria fue hecha a través de grupos de Facebook de los propios programas y por Twitter. Asimismo, tomando elementos del método de la bola de nieve, se identificó a potenciales entrevistados y, a su vez, se les solicitó que compartan a través de sus redes sociales la convocatoria para llegar a otras personas mayores de 18 años, que miraran televisión y hubieran seguido la cobertura del asesinato de Pastorizzo.-

Se utilizaron las entrevistas semiestructuradas porque "se basan en una guía de asuntos o preguntas y el entrevistador tiene la libertad de introducir preguntas adicionales para precisar conceptos u obtener mayor información" (Hernández Sampieri et al., 2014, p. 403). Se elaboró un guion de entrevista para promover el diálogo y se usaron fragmentos de programas (el propósito de esta técnica fue que las imágenes sirvieran como un disparador para comenzar a conversar). El objetivo fue reconstruir las percepciones en torno a este caso a partir del consumo mediático; por ello, el tipo de pregunta que predominó fue de opinión o de expresión de sentimientos (Mertens, 2010).

Una vez hechas las entrevistas, se recurrió al análisis del discurso para su abordaje y sistematización; aquí fueron identificados los ejes temáticos más recurrentes. Finalmente, hubo un consentimiento informado, una herramienta para respaldar el uso de los testimonios y una garantía ética del resguardo de la identidad de los participantes.

Como ya se mencionó, un trabajo previo indagó sobre el tratamiento que realizaron del acontecimiento; es por ello que en esta etapa de la investigación acercarnos al análisis en recepción nos permite observar y analizar la circulación de los sentidos. Coincidimos con Grillo et al. (2016), quienes afirman que uno de los aportes más sustanciales de los estudios de recepción es ubicar el problema en el ámbito de la circulación: "Seguramente, ninguna teoría podrá dar cuenta de todo, pero el objetivo de proponer haces de luz, clivajes, líneas interpretativas novedosas en este sentido no debería ser abandonado por la complejidad del presente desafí" (2016, p. 243).

\section{Resultados}

A partir de la sistematización y análisis de las entrevistas construimos tres categorías sobre los aspectos más reiterados: a) medios de comunicación, 
la manera como los entrevistados y las entrevistadas valoran y entienden la función de los medios. b) Nahir, nos detenemos en la mención sobre aspectos físicos o psíquicos de la joven. c) Asesina mujer, nos referimos al énfasis en el hecho de que una mujer cometió el asesinato.

\section{Medios de comunicación}

Uno de los aspectos más reiterados en las entrevistas tuvo que ver con el rol de los medios. No es un dato menor que la credibilidad que las audiencias otorgan a los medios y a las noticias que consumen incide en la decodificación de las mismas. Dos hechos se reiteraron: por un lado, una suerte de desconfianza generalizada sobre los medios; esta apreciación coincide con el estudio de Layton sobre el nivel de confianza y credibilidad que los ciudadanos argentinos les otorgan a los medios de comunicación (2012, citado por Focás y Kessler, 2015). Por otro lado, una valoración explícita de la cobertura del caso.

La desconfianza tiene relación con el tratamiento de la información, vinculado a los intereses de los medios sobre qué mostrar y qué no, y el sensacionalismo que predomina como estética y discurso narrativo. Las siguientes citas ilustran lo dicho:

"No tengo una opinión; me parece que se les da más importancia a los temas pasionales, porque es tipo una novela. Cuando se da mucha repercusión, para mí es más que nada porque quieren que se enteren más de esto que de otras cosas que están pasando" (entrevistado 6).

"Morbosas, como todas las coberturas que hacen de este caso. Morboso y en los últimos tiempos desacertados. Mariana Fabiani le hace un reportaje a Nahir Galarza, la pone en el lugar de carmelita descalza. Me parece que los noticieros tienen una responsabilidad; no veo a un panelista de los programas de la tarde en condiciones de entrevistar a una persona con sentencia por asesinato" (entrevistado 1).

Parecería que el pacto de verosimilitud entre medios y audiencia se vio resquebrajado por una desconfianza. Asimismo, resulta interesante observar que los/as entrevistados/as no mencionaron el canal de televisión, como si la desconfianza se diera de manera general con respecto al rol de los medios.

"Los medios argentinos, últimamente, no me gusta cómo cubren ningún caso, y esto no va a salir del patrón normal" (entrevistado 13).

“Irresponsablemente y por conveniencia, porque hay cosas que venden más y cosas que venden menos. Sea la noticia que sea. En ese caso se hizo mucho 
espamento [sic], vendía, por todo esto que me parece a mí (...). Soy bastante pesimista con el tema de los medios de comunicación" (entrevistado 2).

En cuanto a la valoración de la cobertura, hay dos grupos antagónicos. Quienes consideran que la cobertura fue buena por "neutral", ya que los medios hicieron su trabajo, que es el de buscar noticias. Algunos ejemplos:

"Estuvieron bien, es su trabajo y ellos tienen que buscar la noticia. Creo que dentro de todo estuvo bien" (entrevistado 12).

"Estuvo bien, no trataron de defender a ninguna de las dos partes y estuvo neutral, se puede decir" (entrevistado 7).

Dentro de la valoración positiva hacia la cobertura están quienes rescatan otros aspectos que, por el contrario, se alejan de la mentada neutralidad y enfatizan atributos que convierten a los medios de comunicación en jueces o peritos que demuestran quién es la culpable. Esto se puede advertir en las siguientes respuestas:

“Para mí estuvo bien porque no fueron a lo obvio: el novio la maltrató y ella se defendió. Porque siempre es lo obvio cuando pasa un caso así, que siempre fue el hombre. Para mí acá investigaron bien y no fueron a lo obvio" (entrevistada 10).

"Buena, fue una buena cobertura porque contaron todos los detalles, donde se demuestra que ella lo mató y que es una asesina y por lo tanto tiene que cumplir con la condena que le dieron" (entrevistada 4).

Se desprende la credibilidad del trabajo periodístico y de las fuentes, y que los/as entrevistados/as confunden informar (rol que les cabe a los medios) e investigar, probar y dictar sentencia (actuación que le corresponde a la justicia).

En el otro grupo están quienes enfatizan los aspectos negativos de la cobertura realizada por los medios. Hubo argumentos opuestos en cuanto a la exposición mediática de la victimaria. Por una parte están los que manifiestan que la cobertura no fue la adecuada porque los medios defendían a Nahir.

[La cobertura fue] superficial, tendenciosa porque bancaban a Nahir, buscaban siempre la cuestión de género y no tratarlo como un homicidio (entrevistado 9).

Otros/as entrevistados/as consideran que la cobertura fue inadecuada porque los medios se ocuparon demasiado de Nahir por ser mujer, incluso dejando a la víctima en un segundo plano: 
"Me llamó la atención que al ser una asesina mujer tuvo mucha más intensidad porque la asesina es mujer. Como que en los casos al revés casi no se habla del asesino, sino de la víctima mujer. Acá fue al revés, me parece. Se habló más de la asesina por ser una mujer precisamente que de la víctima. Se hizo el libro de Mauro Z., los programas de chimentos, y eso cuando el asesino es un hombre, eso no se ve" (entrevistada 8).

"Que hicieron foco en la chica y en la cadena perpetua. Fueron muy subjetivos con respecto a otros casos que han tratado de otros asesinos. Cada vez que hay un hombre que mata a una mujer no hay foto y video constante de esa persona: se lo puede nombrar, pero no se le da tanta relevancia" (entrevistada 11).

Quienes valoran negativamente el tipo de cobertura por centrarse en la victimaria y no en la víctima, haciendo un especial foco en el hecho de que la asesina es una mujer, son precisamente mujeres. Ello podría dar cuenta de una mirada más crítica, con cierta lectura en clave de género. Por su parte, el entrevistado 9 -hombre- no está de acuerdo con la cobertura porque entiende que los medios fueron benevolentes con Nahir por tratarse de una mujer.

Así que es interesante reflexionar sobre lo siguiente: la noticia policial cumple con un rol político y pedagógico; además, es un espacio desde el cual se reclama control social (Garland, 2005), a la vez que se tematiza sobre el bien y sobre el mal. Como mencionan Martini y Pereyra (2009):

Son interpretaciones ancladas en matrices culturales cuyos orígenes cruzan los planos de la tradición y de la modernidad, de la religión y la ley, los de la historia y las memorias sociales, cuyos recorridos se organizan durante la constitución del Estado liberal moderno y el aporte de la primera criminología (2009, p. 11).

Desde los relatos sobre el delito se instauran representaciones de la propia identidad y los otros; no se trata de un segmento "inocente" destinado a alimentar el morbo de las audiencias, sino que, por el contrario, está cargado de un sentido e intencionalidad política y pedagógica que los programas se ocuparon de enfatizar. En ese sentido, cabría seguir preguntándonos cómo, en este contexto de mayor visibilización de las demandas feministas, operan los marcos interpretativos de las audiencias.

\section{Nahir}

Otra de las categorías fue la figura de Nahir. Los/as entrevistados/as repararon en su persona en dos aspectos: su juventud y su psique. Dentro de los relatos que se detienen en la juventud están aquellos que articulan 
la edad con la clase social y aquellos que reparan en su edad por la cercanía que les representa, ya sea por tener hijos/as contemporáneos/as de la victimaria o por trabajar con adolescentes.

\begin{abstract}
"Me interesaba el tema de que era joven la chica, y como tengo una hija más o menos de esa edad, por cómo se relacionan los chicos ahora, cómo son las relaciones, porque también está el tema que yo no sé cómo puede ser el novio de mi hija, si puede ser violento o no, o cómo puede llegar a reaccionar ella. Más que nada por eso y por la curiosidad de saber qué llevó a la chica a matar a alguien" (entrevistada 5).
\end{abstract}

“Son adolescentes, tengo hijos adolescentes y la problemática de la adolescencia me preocupa" (entrevistado 1).

"Era tan jovencita la chica que te confunde todo; los primeros días me daba cierto escozor verla en una cárcel o esposada" (entrevistado 12).

Resulta pertinente observar cómo opera la dimensión de la cercanía emocional en aquellos entrevistados/as que tienen hijos/as adolescentes, por cuanto les preocupa e interesa conocer los hechos por la edad de la víctima y de la victimaria. Como si a través de este caso pudieran conocer más el universo juvenil.

Otro de los aspectos más reiterados fue la mente de Nahir.

"La chica estaba loca, porque para mí ella sabía bien lo que hacía, no estaba 'shockeada', para mí estaba cuerda y sabía lo que estaba haciendo porque lo premeditó todo, lo armó todo" (entrevistada 10).

"Con hacer un estudio psicológico de la chica te das cuenta [de] que la piba es una psicópata. Simplemente ver la foto de la chica, la cara de la chica y te das cuenta [de] que es medio rarita" (entrevistado 13).

“Ayer vi la pericia psicológica y me pareció una fantochada lo que estaban diciendo, porque hacía una defensa de género y no del homicidio. Desdibujó las características psicopáticas que tiene Nahir" (entrevistada 14).

El énfasis en la condición psiquiátrica es notorio. En un trabajo anterior, que analizó el caso desde las condiciones de producción en los programas de panelismo, se observó que el encuadre del caso ancla en marcos interpretativos previos que se nutren de la criminología positivista de principios del siglo XX, según la cual el individuo llega al delito por acción de alguna tara mental, y no solo genética, sino psíquica (Elbert, 1998). De acuerdo con Caimari (2012), la criminología argentina cimentó un nuevo 
"sentido común criminológico" que habilitó a los relatos periodísticos policiales para explicar las causas del crimen a partir de patologías individuales, psicológicas o sociales. El encuadre que predominó en los programas remarcaba "la mente criminal de Nahir".

Mencionamos al inicio que uno de los aportes fundamentales de los estudios de recepción es ubicar el problema en el nivel de la circulación; en este sentido, resulta interesante observar que tanto en producción como en recepción se reiteró y enfatizó la perspectiva psiquiátrica de la joven.

\section{Asesina mujer}

Una de las cuestiones más reiteradas fue el hecho de comparar este caso con otros en los que el asesino fue un hombre. Es posible sistematizar dos tipos de posicionamientos. Por un lado, quienes advierten cierta desigualdad en el tratamiento que se le dio al caso por tratarse de una mujer: una suerte de disconformidad por hacer foco en la victimaria y no en la víctima, y por la sobreexposición de Nahir y el escaso interés que suscitó Fernando.

“Mirá, primero que nada, no sé el nombre del chico muerto y el caso tendría que tener el nombre de él” (entrevistado 7).

"Es que todo el tiempo enfocaban a la chica como protagonista, aparecían fotos en los medios, videos de ella. A diferencia de otros casos en que el asesino no aparece tanto" (entrevistada 11).

"Lo que a mí me chocó es que hay muchos femicidas que asesinan y uno no les conoce ni siquiera la cara, ni el color de pelo ni la piel ni los ojos. Y a ella, creo que a todos nos quedó muy marcado, que la asociaban con ese rostro angelical, linda, de rostro angelical y quedó muy marcado el caso con su imagen por estar todo el tiempo en los medios" (entrevistada 11).

“No sé si se trató bien, si se trató mal el tema, porque era todo el tiempo acusar a la chica, acusarla, acusarla; está bien que la acusen porque mató a alguien, pero nadie pensó en el chico. Se murió y nadie habló más del pibe, me parece; todo era '¿y cómo sigue la chica ahora?', ¿qué condena le van a dar?'” (entrevistada 5).

En el otro bando se advierten posiciones que rescatan positivamente el que se haya hablado del caso por la poca visibilidad del hecho cuando quien mata es una mujer:

"Son muy pocos los casos de mujeres porque no se dan a conocer mucho, pero hay casos de mujeres también que son maltratadoras psíquicamente y que pegan 
al hombre también; por eso me interesó seguir el caso. Creo que es el único caso, conocido, famoso, de una mujer que maltrate y mate" (entrevistada 10).

"Observo que muchas veces no se tiene en cuenta que también hay acoso y obsesiones de parte de las chicas a los chicos y suele darse mucho en la adolescencia; no tengo estadísticas, pero lo veo en el día a día" (entrevistado 1).

El contexto histórico que se está atravesando en materia de género y ampliación de derechos ${ }^{2}$ en Argentina no es un dato menor en cierto clima de época que aparece en las entrevistas como referencia más allá de las diferentes opiniones. En los últimos cinco años se han visibilizado aún más las voces y demandas de las mujeres, especificamente desde la primera marcha del Ni una Menos, llevada a cabo el 3 de junio de 2015, así como el debate de la legalización del aborto y las denuncias de algunas actrices por abusos y maltratos de parte de algunos actores.

Los medios de comunicación, no sin tensiones, no pudieron ignorar este reclamo social y se visibilizó la violencia hacia las mujeres, lo que generó nuevas tensiones a propósito de las representaciones y estereotipos. En Argentina, según un informe del Instituto de Políticas de Género Wanda Taddei (Papaleo, 2017) una mujer era asesinada cada 18 horas por violencia de género; asimismo el informe indicaba que el concepto de femicidio ${ }^{3}$ comenzaba a ser más usado. Las entrevistas muestran una reiteración en torno al contexto histórico:

"Estamos en un contexto que se habla mucho de feminismo, del tema del aborto, y tuvo mucha resonancia que una mujer haya matado a un hombre y el caso se haya resuelto mil veces más rápido que al revés" (entrevistada 3).

“Fue en un momento que había muchos femicidios y justo aparece la figura de una mujer, la asesina es una mujer y eso fue lo chocante, justo en un contexto de tanto femicidio; aparte la edad, que es una edad que siempre suele ser víctima la mujer" (entrevistada 8).

“En este caso, como es del género femenino, como que se le dio más identidad. Se dramatizó mucho más, siendo que tenemos más homicidios a mujeres, porque lo había cometido una mujer" (entrevistada 14).

De las entrevistas se desprende cierta necesidad de contextualizar el hecho para hacer un juicio de valor crítico sobre el tratamiento del caso.

En tensión con lo mencionado, en las entrevistas también se observa una fuerte reiteración a la hora de enmarcar el asesinato de Pastorizzo como
2 Ley de Prevención y Sanción de la Trata de Personas y Asistencia a sus Víctimas (26.364/08), Ley de Educación Sexual Integral (26.150/06), Ley de Protección integral para Prevenir, Sancionar y Erradicar la Violencia Contra las Mujeres (26.485/09), Ley de Matrimonio Igualitario $(26.618 / 10)$ y de Identidad de Género (26.743/12).

3 La ley 26.791/12 introdujo en el artículo 80 del Código Penal argentino la aplicación de la reclusión perpetua o prisión perpetua al que matare "a su ascendiente, descendiente, cónyuge, excónyuge, o a la persona con quien mantiene o ha mantenido una relación de pareja (...) a una mujer cuando el hecho sea perpetrado por un hombre y mediare violencia de género". 
violencia de género; esto demuestra desconocimiento o confusión sobre este concepto ${ }^{4}$. Algunos ejemplos:

Lo tomo como un caso de violencia de género, pero a la inversa (...) No es nuevo que una chica se obsesione con un chico, lo he visto siendo yo adolescente. (entrevistado 1).

“Para mí siempre fue claro que hay violencia de género inversa. Cuando se salió a decir que porque era mujer se había hecho un juicio abreviado, se comprobó que en Entre Ríos había habido un caso exactamente igual, pero inverso: un chico mata a una chica y en el término de seis meses por juicio abreviado el chico estaba preso, con lo cual funciona el concepto de igualdad ante la ley" (entrevistado 1).

"Es una mujer la que mató a un hombre en un momento en que todo gira en torno a la violencia de género, pero para el lado femenino" (entrevistado 13).

Además de la confusión sobre lo que es violencia de género en el relato de los hombres, también opera en resignificar el caso poniendo en discusión solapada la desigualdad entre hombres y mujeres. En un trabajo previo ya mencionado, sobre el tratamiento del caso en los programas de panelismo de la televisión (Heram y Gago, 2019), se observó que en estos había una suerte de tensión entre el mencionar aspectos vinculados con la violencia de género $y$, a su vez, desmarcar el caso de dicha perspectiva. Esto se puso en evidencia en la incomodidad y desconocimiento de las conductoras y los/as panelistas, y en cierta confusión también en torno a qué es la violencia de género.

\section{Discusión y conclusiones}

Entre las instancias de producción y las de recepción hay desfasaje (Verón, 2014a). Por eso, el estudio de las condiciones de la producción no permite deducir los efectos de un discurso. Si bien en trabajos previos hubo un análisis desde la producción, en este nos propusimos realizar un análisis en recepción con el fin de indagar entre las percepciones de los televidentes y las televidentes sobre el tratamiento que recibió el asesinato de Pastorizzo en los programas de televisión.

Sistematizamos en tres grandes zonas los aspectos más reiterados: la propia reflexión sobre los medios de comunicación, otro aspecto ligado a la figura de Nahir y, por último, el hecho de que el asesinato fue cometido por una mujer. Si bien los medios de comunicación no son los únicos agentes que intervienen en la construcción de la opinión y percepción sobre asuntos públicos, y esto ya lo advirtieron autores como Lazarsfeld (1962) en la
4 "Se entiende por violencia de género el ejercicio de la violencia que refleja la asimetría existente en las relaciones de poder entre varones y mujeres, y que perpetúa la subordinación y desvalorización de lo femenino frente a lo masculino. Esta se caracteriza por responder al patriarcado como sistema simbólico que determina un conjunto de prácticas cotidianas concretas" (Rico, 1996). 
década del 40 o, en el orden local, estudios más recientes y enfocados en los temores sociales como el de Focás (2017), de los resultados obtenidos podemos afirmar que entre la instancia de producción y la instancia de recepción hubo concordancia en varios puntos.

El contexto de debate público en torno a la violencia de género, entre otros temas vinculados a géneros y sexualidades, funcionó como comparación y contraste para interpretar y resignificar el caso aquí analizado. Tanto en producción como en recepción se evidenció desconocimiento o confusión sobre a qué se hace referencia cuando se habla de dicha violencia. En el caso de los medios, la tensión en cuanto a la perspectiva de género se ve en menciones a aspectos vinculados con la violencia de género y mensajes que se desmarcan de esta mirada o muestran ignorancia sobre la problemática. En las entrevistas se enmarcó el asesinato de Pastorizzo como violencia de género, lo que muestra cierta confusión sobre el concepto.

Por otra parte, se observó que el caso interpeló a varios de los/as entrevistados/ as en función de la cercanía emocional: por tener hijos/as de esa edad o por estar en contacto con adolescentes o jóvenes en sus ámbitos laborales (preceptores y docentes). También prevaleció una mirada de desconfianza general frente a los medios de comunicación y en este caso en particular se corroboró cierta disconformidad con respecto a la cobertura.

Hay que decir que aunque los medios son cuestionados por su credibilidad, el público los sigue consumiendo e, inclusive, adhiriendo a muchos de los núcleos argumentativos desplegados en las coberturas. Estos datos parciales que surgen del estudio merecen mayor profundización en futuros trabajos.

Finalmente, los resultados obtenidos arrojan nuevas preguntas de investigación que nos interesa seguir ampliando: ¿qué sentidos se construyen frente a la cobertura de casos en los que las mujeres son las víctimas? ¿La incidencia mediática sobre la recepción de casos conmocionantes, como el aquí analizado, varía según los géneros televisivos que se consumen?

\section{Referencias}

AA. VV. (2018). Estudio cuantitativo sobre consumo de medios en la ciudad de Rosario, Argentina. Cemop.

Becerra, M., Kessler, G., Raimondo Anselmino, N., Aruguete, N., Focás, B., Retegui, L., Carboni, O. y Rodríguez, C. (2020). La TV insegura. Estudio del circuito productivo de las noticias sobre delito, violencia e inseguridad en noticieros de Buenos Aires, Córdoba, Rosario y Mendoza. En S. Poliszuk y A. Barbieri, Medios, agendas y periodismo en la construcción de la realidad. Editorial UNRN. 
Boito, M. E.; Gago, S. y Valor, M. N. (2017). Una aproximación a la estetización de la política en la oferta televisiva argentina contemporánea. Astrolabio, 19, 69-95. https: / / revistas. unc.edu.ar/index.php/astrolabio/article/view/18038

Caimari, L. (2012). Mientras la ciudad duerme. Pistoleros, policías y periodistas en Buenos Aires, 1920-1945. Siglo XXI.

Calzado, M., Lío, V., Manchego Cárdenas, C. e Irisarri, V. (2020). De la producción a la recepción. Una propuesta de observación multilocal y sincrónica para el análisis de noticias televisivas. Empiria. Revista de Metodología de Ciencias Sociales, 47, 185- 212. doi: 10.5944/empiria.47.2020.27429

Checa Montúfar, F. (2011). De la recepción al "consumo": una necesaria reflexión conceptual. En Jacks, N. (Coord.). Análisis de recepción en América Latina: un recuento histórico con perspectivas al futuro (pp. 13-17). Editorial Quipus.

Denzin, N. K. y Lincoln, Y. (Coord.) (2012). Manual de investigación cualitativa. Las estrategias de investigación cualitativa. Gedisa.

Duek, C. (2014). Consumos culturales en Argentina: tecnología, dispositivos y prácticas. En V. Papalini, Promesas y traiciones de la cultura masiva. Balance de 30 años de democracia en Argentina (pp. 155-179). Edulp.

Elbert, C. A. (1998). Manual básico de criminología. Eudeba.

Fernández Pedemonte, D. (2010). Conmoción pública: los casos mediáticos y sus públicos. La Crujía.

Flick, U. (2004). Introducción a la investigación cualitativa. Morata.

Focás, B. (2017). Apropiaciones de los públicos en torno a la noticia de inseguridad. Astrolabio, 19, 6-31.

Focás, B. y Kessler, G. (2015). Inseguridad y opinión pública: Debates y líneas de investigación sobre el impacto de los medios. Revista Mexicana de Opinión Pública, 19, 41-58. DOI: http://dx.doi.org/10.1016/j.rmop.2015.07.001

Garay Cruz, L. M. (2006). ¿Qué ha cambiado y qué sigue igual? Reflexiones sobre el concepto de audiencia mediática. Digital Universitaria, 7 (6), 1-10.

García Canclini, N. (1995). Consumidores y ciudadanos. Conflictos multiculturales de la globalización. Grijalbo.

Garland, D. (2005). La cultura del control: crimen y orden social en la sociedad contemporánea. Gedisa.

Glaser, B. y Strauss, A. (1967). The discovery of grounded theory: strategies for qualitative research. Aldine.

Grillo, M., Papalini, V. y Benítez Largui, S. (2016). Estudios sobre consumos culturales en la Argentina contemporánea. Clacso.

Grimson, A. y Varela, M. (1999). Audiencias, cultura y poder. Estudios sobre la televisión. Eudeba.

Guber, R. (2011). La etnografía. Método, campo y reflexividad. Siglo XXI.

Hall, S. (1980). Codificar/decodificar. En Culture, media and language [Traducción Silvia Delfino]. Hutchinson.

Hernández Sampieri, R., Fernández Collado, C. y Baptista Lucio, M. P. (2014). Metodología de la investigación. Interamericana Editores. 
Heram, Y. (2018). Why Showmatch? An approach to television consumption of one of the most watched programs in Argentina. Revista Fonseca, Journal of Communication, 16, 177-190. doi: https: / / doi.org/10.14201/fjc201816171184

Heram, Y. y Gago, M. P. (2019). Panelismo y noticia policial. Un análisis sobre la cobertura televisiva del asesinato de Fernando Pastorizzo. Dixit, (30), 04-21. doi: https:// doi. org/10.22235/d.v0i30.1722

Hoggart, R. (1990). La cultura obrera en la sociedad de masas. Grijalbo.

Jacks, N. (2011). Análisis de recepción en América Latina: un recuento histórico con perspectivas al futuro. Quipus.

Justo von Luzer, C., Rovetto, F. y Spataro, C. (2018). Las audiencias de los programas televisivos de chimentos. Percepciones y criterios morales sobre géneros, sexualidades y derechos. Astrolabio, 20, 233-255.

Landi, O. (1992). Devórame otra vez. Qué hizo la televisión con la gente. Qué hace la gente con la televisión. Planeta.

Landi, O., Vacchieri, A. y Quevedo, L. A. (1990). Públicos y consumos culturales de Buenos Aires. Cedes.

Lazarsfeld, P. (1962). El pueblo elige: estudio del proceso de formación del voto durante una campaña presidencial. Paidós.

Ludmer, J. (1999). El cuerpo del delito. Un manual. Perfil.

Mata, M. C. (1997). Públicos y consumos culturales en Córdoba. Centro de Estudios Avanzados, Universidad Nacional de Córdoba.

Martín Barbero, J. (1987). De los medios a las mediaciones. Gustavo Gili.

Martini, S. y Pereyra, M. (2009). La irrupción del delito en la vida cotidiana. Biblos.

Mattelart, M. y Piccini, M. (1974). La televisión y los sectores populares. Revista Comunicación y Cultura, (2).

Mattelart, A. y Neveu, E. (2002). Los cultural studies. Hacia una domesticación del pensamiento salvaje. Ediciones de Periodismo y Comunicación, UNLP.

McQuail, D. (1999). Introducción a la teoría de la comunicación de masas. Paidós Comunicación.

Mertens, D. M. (2010). Research and evaluation in education and psychology: integrating diversity with quantitative, qualitative, and mixed methods. Sage Publications

Moguillansky, M. y Aliano, N. (2017). De los consumos a las prácticas culturales. Una mirada desde las articulaciones biográficas. Astrolabio, 19, 96-117.

Moguillansky, M. y Papalini, V. (2017). Los públicos de artes combinadas en Argentina. Una revisión de las agendas de investigación. Revista Pilquen Sección Ciencias Sociales, 20 (3), 44-55.

Morley, D. (1992). Television, audiences and cultural studies. Routledge.

Papaleo, C. (2017). Femenicidios en Argentina. http:/ / feim.org.ar/2017/02/14/feminicidiosen-argentina/

Rico, N. (1996). Violencia de género: un problema de Derechos Humanos. Comisión Económica para América Latina y el Caribe. https://www.cepal.org/mujer/noticias/ paginas/3/27403/violenciadegenero.pdf

Saintout, F. y Ferrante, N. (2006). Los estudios en recepción en Argentina hoy: rupturas, continuidades y nuevos objetos. Diálogos de la comunicación, 73, 19-26. https://n9.cl/by5j 
Saítta, S. (2013). Regueros de tinta. El diario Crítica en la década de 1920. Siglo XXI.

Segura, S., Longo, V., Hidalgo, A. L., Traversaro, N., Linares, A., Vinelli, N. A., y Espada, A.

(2018). Los públicos de medios comunitarios, populares y alternativos en América Latina.

El caso argentino. Commons, 7 (1), 5-45.

Sistema de Información Cultural de la Argentina [SInCA]. (2017). Encuesta Nacional de Consumos Culturales y Entorno Digital.

Sunkel, G. (2002). Una mirada otra: la cultura desde el consumo. Clacso.

Terrero, P. (1997). Ocio, prácticas y consumos culturales. Aproximación a su estudio en la sociedad mediatizada. Diálogos, 49, Felafacs, 78-87.

Verón, E. (1995). Investigación, semiología y comunicación: del estructuralismo al análisis en producción. Causas y Azares, 3, 7-23.

Verón, E. (2014a). El fin de la historia de un mueble. En M. Carlón y C. A. Scolari, El fin de los medios masivos. El debate continúa (pp. 285-303). La Crujía.

Verón, E. (2014b). Teoría da midiatização: uma perspectiva semioantropológica e algumas de suas consequências [PDF]. Revista Matrizes, 1, 13-19. http://portal.pucminas.br/ imagedb/documento/DOC_DSC_NOME_ARQUI20180205111629.pdf

Wortman, A. (2015). Consumos culturales en Buenos Aires: una aproximación a procesos sociales contemporáneos. Universidad de Buenos Aires. 